\title{
ENRIQUECIMENTO DE MACARRÃO TIPO TUBO (MASSA CURTA) COM DERIVADOS DE LEVEDURA (Saccharomyces Sp.): IMPACTO NUTRICIONAL E SENSORIAL ${ }^{1}$
}

\author{
Marjorie Carelli Costa SANTUCCI², Izabela Dutra ALVIM², Flávio SCHMIT², Eliete Vaz de FARIA², \\ Valdemiro Carlos SGARBIERI ${ }^{2, *}$
}

\begin{abstract}
RESUMO
Esta pesquisa teve como objetivo investigar a viabilidade técnica e os melhores níveis de adição dos derivados de levedura, autolisado (AT) e extrato (Ex) ao macarrão, visando uma melhoria do valor nutritivo sem diminuir a sua aceitação pelo consumidor. Adição de 5 ou de $7,5 \%$ de derivado de levedura melhorou o escore de aminoácidos essenciais (EAE) de 9 e $19 \%$, respectivamente, para o AT e o Ex. O índice que mede a capacidade da proteína de promover crescimento (NPR) se elevou de 25 e $40 \%$ para a adição de $7,5 \%$ de autolisado ou de extrato, respectivamente. No macarrão massa branca, a adição de 5\% de Ex não alterou a aceitação do produto, contudo 5\% de AT teve um impacto negativo na aceitação pelo consumidor. A adição à massa de extrato de espinafre (massa verde) de $7,5 \%$ de derivado de levedura afetou apenas a aparência do macarrão adicionado de extrato e a aparência e a cor do macarrão com $7,5 \%$ de autolisado, em relação ao macarrão contendo apenas extrato de espinafre. A adição de espinafre à massa melhorou as características sensoriais do macarrão adicionado de $7,5 \%$ de autolisado. As características tecnológicas de fabricação dos macarrões não foram alteradas pela adição à massa dos derivados de levedura.

Palavras-chave: macarrão; enriquecimento; derivados de levedura; extrato; autolizado
\end{abstract}

\section{SUMMARY}

ENRICHMENT OF NOODLES (SHORT TUBE) WITH YEAST (Saccharomyces sp.) DERIVATIVES: NUTRITIONAL AND SENSORIAL IMPACT The objective of this work was to investigate the technical possibility and best levels of addition to noodles of yeast autolysate (AT) and extract (Ex) aiming at improving nutritive value without a decrease in consumer acceptance. Addition of 5 or $7.5 \%$ yeast derivative improved essential aminoacid score (EAS) of 9 and 19\%, respectively, for the AT and the Ex. The growth promoting index (NPR) increased 25 and $40 \%$ for the $7.5 \%$ addition of AT or Ex, respectively. In the white noodles, $5 \%$ addition of extract did not alter the acceptance of the product, however $5 \%$ addition of autolysate produced a negative impact on the consumer acceptance. Addition to the mass of spinach extract (green noodle) and $7.5 \%$ of yeast derivative affected only the appearance of the noodle added of yeast Ex and also the appearance and color of the noodle added of AT, compared with the noodle added of spinach extract only. Addition to the mass of spinach extract improved the sensorial properties of the noodle added of $7.5 \%$ AT. The manufacturing technological characteristics of the noodles were not altered by the addition to the mass of yeast derivatives.

Keywords: enrichment; yeast derivate; extract; autolysate.

\section{1 - INTRODUÇÃO}

A levedura é reconhecida mundialmente como uma excelente fonte de proteínas, vitaminas do complexo B, minerais essenciais e fibra dietética [16].

O Brasil é o maior produtor mundial de álcool etílico a partir de cana-de-açúcar, com uma produção estimada de mais de 12 bilhões de litros anuais. A fermentação etanólica usa a levedura Saccharomyces cerevisiae, como agente da fermentação. A prática operacional, nas destilarias de álcool, gera um excedente de levedura da ordem de 20 a 30kg de biomassa seca por $\mathrm{m}^{3}$ de álcool produzido [14]. Esse processo de "sangria" da levedura das dornas de fermentação gerava, em 1996 [9] algo ao redor de 230 ton/ano de levedura seca como subproduto, que é normalmente descartada ou usada apenas em ração para animal.

Vários estudos têm sido realizados visando o uso da levedura e alguns de seus derivados em alimentação humana [5, 6, 7, 10, 13].

A autólise de levedura é considerada um processo irreversivel, que resulta na morte das células. Durante a autólise, a atividade das enzimas respiratórias diminui enquanto que a atividade das hidrolases aumenta [3].

Recebido para publicação em 22/06/2002. Aceito para publicação em 27/01/2003 (000871).

2. Instituto de Tecnologia de Alimentos (ITAL), Av. Brasil, 2. 880, CEP 13073001, Campinas, SP.

* A quem a correspondência deve ser enviada.
Autolisados e extratos de levedura têm sido tradicionalmente usados na indústria alimentícia como ingredientes saborizantes de sopas, molhos, produtos de panificação e produtos cárneos [6, 7, 10].

Um processo para produção piloto de derivados de levedura (Saccharomyces sp.) para uso como ingrediente na formulação de alimentos foi desenvolvido em nosso laboratório [19].

Neste trabalho são descritos a produção de macarrões enriquecidos com autolisado ou com extrato de levedura originária de destilaria de álcool etílico e seus efeitos sobre o valor nutritivo da proteína e na aceitação do produto final, pelos consumidores.

\section{2 - MATERIAIS E MÉTODOS}

\section{1 - Ingredientes utilizados na formulação dos ma- carrões}

As misturas para a preparação do macarrão padrão e dos macarrões enriquecidos com derivados de levedura (extrato ou autolisado) ou derivado de levedura mais espinafre são mostradas na Tabela 1.

Os derivados de levedura foram produzidos a partir da levedura residual de destilaria de álcool etílico, após os seguintes tratamentos: lavagem para eliminar impurezas e sólidos solúveis contaminantes; autólise $\left(55^{\circ} \mathrm{C}\right.$, pH 5,5, 24h); desidratação (spray) de parte do autolisado para obtenção do autolisado (AT) desidratado; centrifu- 
gação do autolisado para obtenção do extrato (sobrenadante); concentração à vácuo e desidratação (spray) para obtenção do extrato (Ex) desidratado.

TABELA 1. Ingredientes e proporções utilizadas na formulação de um macarrão padrão tubo (massa curta) e de macarrões enriquecidos com derivado de levedura ou derivado de levedura mais espinafre.

\begin{tabular}{lcccc}
\hline \multirow{1}{*}{$\begin{array}{c}\text { Ingredientes } \\
\text { (g) }\end{array}$} & Padrão & $\begin{array}{c}\text { Enriquecido } \\
\text { (5\% derivado) }\end{array}$ & $\begin{array}{c}\text { Enriquecido } \\
(\mathbf{7 , 5 \%} \text { derivado) }\end{array}$ & $\begin{array}{c}\text { Enriquecido } \\
(\mathbf{7 , 5 \%} \text { derivado } \\
\mathbf{+} \text { es pinafre) })^{1}\end{array}$ \\
\cline { 2 - 5 } & & 6.000 & 6.000 & 5.000 \\
\hline Farinha de trigo & 6.000 & 1,04 & 1,04 & - \\
$\beta$-caroteno & 1,04 & 1.800 & 1.800 & 1.050 \\
Água (mL) & 1.800 & 300 & 450 & 375 \\
Levedura (Ex) & - & 300 & 450 & 375 \\
Levedura (AT) & - & - & - & 25 \\
Espinafre & - & & & \\
(Corantec) & & & & \\
\hline
\end{tabular}

${ }^{1}$ (\% de adição de extrato ou autolisado de levedura).

\section{2 - Processamento dos macarrões}

A massa foi preparada em misturador e, em seguida, extrusada em uma extrusora própria para macarrão (Braibanti \& Cia, Milano, Itália).

A secagem foi feita em estufa de circulação de ar (Proctor \& Schwartz Inc., Philadelphia, USA), com a seguinte monitoração da temperatura: bulbo seco $75^{\circ} \mathrm{C}$ e bulbo úmido $73^{\circ} \mathrm{C}(2,5 \mathrm{~h})$; bulbo seco $55^{\circ} \mathrm{C}$ e bulbo úmido $53^{\circ} \mathrm{C}(0,5 \mathrm{~h})$; bulbo seco $45^{\circ} \mathrm{C}$ e bulbo úmido $43^{\circ} \mathrm{C}$ (40 min); ventilação para completar a secagem por $1 \mathrm{~h}$.

\section{3 - Determinações químicas}

Composição centesimal. A composição centesimal foi determinada nos derivados, extrato e autolisado de levedura, e nos macarrões formulados e processados.

Proteína bruta $(\mathrm{N} \times \mathrm{F})$, teor de umidade e cinzas foram determinados pelos métodos descritos no A.O.A.C. [1]. Lipídios totais pelo método de BLIGH \& DYER [4]. Fibra alimentar total foi determinada pelo método de ASP et al [2]. Ácido ribonucléico (RNA) foi determinado pelo método colorimétrico de HERBERT et al [12]. Os carboidratos foram determinados por diferença entre $100 \%$ e a soma das porcentagens dos demais componentes da amostra.

Composição em aminoácidos. A composição em aminoácidos e os escores de aminoácidos essenciais foram determinados para o autolisado e o extrato de levedura e para os macarrões, de formulação padrão e enriquecidos.

A análise foi feita após hidrólise ácida das amostras ( $\left.\mathrm{HC1} 6 \mathrm{~N}, 100^{\circ} \mathrm{C}, 22 \mathrm{~h}\right)$, seguida da eliminação do $\mathrm{HCl}$ por evaporação sob vácuo. O resíduo da evaporação, contendo a mistura de aminoácidos, foi ressuspenso em tam-

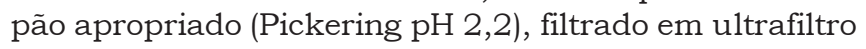

de $0,25 \mu \mathrm{m}$ e uma aliquota apropriada foi aplicada na coluna de troca catiônica de um analisador Dionex Dx-300 para separação dos aminoácidos. A quantificação foi feita por reação colorimétrica, pós-coluna, com ninidrina e os aminoácidos identificados através de uma mistura padrão de aminoácidos (Pierce Kit 22), com base nos tempos de retenção.

\section{4 - Avaliação sensorial dos macarrões}

O macarrão produzido através da formulação padrão e os enriquecidos com derivados de levedura ou derivados de levedura mais extrato de espinafre foram submetidos à avaliação sensorial de aceitabilidade, com a participação de 45 consumidores habituais de massas (homens e mulheres), na faixa etária entre 15 e 55 anos.

Avaliou-se a aceitabilidade dos produtos em relação à aparência, cor, textura, sabor e aceitação global. Utilizou-se escala hedônica de 9 pontos ( 9 = gostei extremamente, 5 = não gostei nem desgostei e 1 = desgostei extremamente). Para os testes, as amostras foram apresentadas em códigos de 3 dígitos aleatórios, segundo delineamento em blocos completos casualizados [15]. Os testes foram conduzidos em cabines individuais iluminadas com lâmpadas fluorescentes, sendo a coleta e a análise dos dados realizadas por um sistema computadorizado (Compusense Five), versão 3.8. Os dados obtidos através da escala hedônica foram submetidos à análise de variância e teste de Tukey para comparação das médias, ao nivel de significância de $5 \%(p<0,05)$.

\section{5 - Avaliação nutricional dos macarrões}

A avaliação nutricional foi feita para o macarrão de formulação padrão e para os enriquecidos com extrato de espinafre e derivados de levedura. Para esta avaliação, utilizaram-se a composição centesimal, o escore de aminoácidos essenciais (EAE) [8], o escore de aminoácidos essenciais corrigido pela digestibilidade verdadeira da proteína (PDCAAS) [11], além da digestibilidade verdadeira (Dv) e do quociente de utilização líquida da proteína (NPR), determinados através de ensaio biológico com ratos [18].

Para o ensaio foram utilizados 40 ratos machos recém-desmamados da linhagem Wistar, livres de patógenos específicos (SPF), fornecidos pelo Centro de Bioterismo (CEMIB) da UNICAMP. Os ratos foram distribuídos aleatoriamente em 5 grupos de 8 ratos cada e mantidos em gaiolas individuais em ambiente com temperatura controlada a $22 \pm 2{ }^{\circ} \mathrm{C}$ e períodos alternados de claro-escuro de $12 \mathrm{~h}$.

A duração total do ensaio foi de 21 dias, sendo que nos primeiros 7 dias computou-se apenas o consumo de dieta e o ganho de peso dos ratos de cada grupo. Na segunda semana, além de registrar o consumo e o ganho de peso foram coletadas as fezes, de cada rato, para determinação do nitrogênio excretado e cálculo da digestibilidade. Na última semana, continuou-se registrando o consumo de dieta e o ganho de peso. Durante os 21 dias do ensaio, os ratos receberam dieta e água ad libitum. 
Os indices determinados experimentalmente foram a digestibilidade verdadeira da proteina $(\mathrm{Dv} \%=$ nitrogênio absorvido/nitrogênio ingerido x 100), sendo que o nitrogênio absorvido foi determinado pela diferença entre o nitrogênio ingerido e o nitrogênio excretado nas fezes, já corrigido pelo nitrogênio de origem endógena excretado nas fezes de um grupo em dieta aprotéica (sem adição de proteína). Para o cálculo do quociente de utilização líquida da proteína usou-se a relação $(\mathrm{NPR}=$ ganho de peso (g) do grupo em $10 \%$ proteína + perda de peso (g) do grupo em dieta aprotéica/consumo de proteína (g) do grupo em dieta com $10 \%$ proteina).

As dietas experimentais foram preparadas com $10 \%$ de proteina fornecida pelos diferentes macarrões, além da dieta com 10\% de caseina (proteína padrão) e uma dieta aprotéica. Na composição das dietas, exceto pelo nivel de proteina de $10 \%$ ao invés de $17 \%$, e da dieta aprotéica (sem proteína), seguiu-se a recomendação do "American Institute of Nutrition", AIN-93 [17] para ratos em crescimento. A diferença em proteína foi compensada por amido e os macrocomponentes dos macarrões (carboidrato, lipídios e proteina) foram considerados na composição das dietas.

\section{6 - Análise estatística}

Os dados experimentais foram submetidos à análise de variância (ANOVA) e as diferenças entre médias foram avaliadas pelo teste de Tukey.

\section{3 - RESUltadoS E DISCUSSÃo}

\section{1 - Composição centesimal dos derivados de leve- dura e dos macarrões}

Na Tabela 2 é apresentada a composição centesimal do autolisado (AT) e do extrato (Ex) de levedura, usados como ingredientes de enriquecimento e dos macarrões com ou sem espinafre, contendo um desses ingredientes ao nivel de 5 ou $7,5 \%$ de adição.

Com relação aos derivados de levedura (AT e Ex) notase no AT uma predominância (32\%) de fibra alimentar, sendo principalmente do tipo solúvel, enquanto que no extrato predominam os componentes proteina $(48,4 \%)$, cinzas $(10,8 \%)$, ácidos ribonucléicos $(7,9 \%)$ e carboidratos $(24,8 \%)$. O elevado teor de cinzas se deve, em boa parte, ao $\mathrm{NaCl}$ adicionado ao meio de fermentação, como plasmolizante, durante a operação de autólise da levedura [19]. Por outro lado, o teor de carboidratos é, em boa parte, proveniente da adição de maltodextrina $(25 \%$ em relação aos sólidos do extrato), antes da secagem em spray.

Com relação aos macarrões, observa-se que a adição de 5 ou $7,5 \%$ de derivado de levedura não alterou sensivelmente a composição da massa, podendo-se notar um aumento no teor de proteina, na faixa de 11 para $14 \%$, um aumento nos teores de fibra, na faixa de 3 até $5,7 \%$ e no teor de umidade, de $12 \%$ no macarrão padrão a $13,5 \%$ no macarrão com $7,5 \%$ de derivados de levedura (AT ou Ex). Nota-se também uma diminuição propor- cional no teor de carboidratos do macarrão de formulação padrão, de $71,6 \%$ para $63,5 \%$ para o produto com $7,5 \%$ de derivado (AT ou Ex) de levedura.

TABELA 2. Composição centesimal de um autolisado (AT) e de um extrato (Ex) de levedura e de macarrões enriquecidos ou não com extrato de espinafre e um dos derivados de levedura.

\begin{tabular}{|c|c|c|c|c|c|c|c|c|}
\hline \multirow[b]{2}{*}{ Componente $e^{*}$} & \multirow[b]{2}{*}{ АT } & \multirow[b]{2}{*}{ Ex } & \multicolumn{6}{|c|}{ Macarrões } \\
\hline & & & $M$ & M-AT & M-Ex & M-ES & M-ES-AT & M-ES-Ex \\
\hline & & & & $5 \%$ & $5 \%$ & & $7,5 \%$ & $7,5 \%$ \\
\hline $\begin{array}{l}\text { Proteína } \\
(\mathrm{N} \times \mathrm{F})^{1}\end{array}$ & 38,4 & 48,4 & 11,1 & 12,4 & 12,7 & 12,0 & 14,1 & 14,3 \\
\hline $\begin{array}{l}\text { Fibra alimentar } \\
\text { total }\end{array}$ & 32,0 & 3,1 & 2,8 & 5,2 & 3,8 & 4,2 & 5,7 & 4,1 \\
\hline Lipídios totais & 1,2 & 0,4 & 1,7 & 1,8 & 2,0 & 1,6 & 1,7 & 1,6 \\
\hline Cinzas & 6,0 & 10,8 & 0,8 & 1,0 & 1,3 & 0,7 & 1,1 & 1,4 \\
\hline Umidade & 3,5 & 4,6 & 12,0 & 12,2 & 13,5 & 12,7 & 13,3 & 13,5 \\
\hline $\begin{array}{l}\text { Ácido } \\
\text { ribonucléico }\end{array}$ & 5,4 & 7,9 & nd & nd & nd & nd & nd & nd \\
\hline $\begin{array}{l}\text { Carboidratos } \\
\text { (diferença) }\end{array}$ & 13,5 & 24,8 & 71,6 & 67,4 & 66,7 & 68,8 & 63,7 & 63,5 \\
\hline
\end{tabular}

* Resultados representam a média de 2 determinações em amostras independentes ${ }^{1} \mathrm{~F}=5,8$ para o AT e Ex de levedura. $\mathrm{F}=6,25$ para os macarrões.

$\mathrm{M}=$ macarrão de formulação padrão; M-AT, macarrão padrão adicionado de $5 \%$ de autolisado; M-Ex, macarrã̃o padrão com $5 \%$ de extrato; M-ES, formulação padrão adicionada de extrato de espinafre; M-ES-AT e M-ES-Ex, macarrões adicionados de espinafre mais $7,5 \%$, respectivamente de AT ou Ex; nd = não determinado.

\section{2 - Composição em aminoácidos dos derivados de levedura (AT ou Ex) e dos macarrões}

A Tabela 3 mostra a composição em aminoácidos do autolisado (AT) e do extrato (Ex) de levedura e de macarrões com espinafre, sem adição e com adição de $7,5 \%$ de autolisado (AT) ou extrato (Ex) de levedura.

A mesma tabela mostra ainda os escores de aminoácidos essenciais calculados com base no aminoácido mais limitante ${ }^{* *}$ ) em referência ao padrão da FAO/WHO [8] para as necessidades de crianças na faixa etária de 2 a 5 anos de idade.

Nota-se que apenas o autolisado (AT) apresentou perfil de aminoácidos essenciais capaz de satisfazer em $100 \%$ o padrão de referência da FAO/WHO. O Ex foi ligeiramente deficiente com um escore (EAE) de 87,8\%, com base na leucina, em relação ao padrão FAO/WHO.

Os macarrões foram todos deficientes em mais de um aminoácido essencial, tendo a lisina como o aminoácido mais deficiente. O menor $\operatorname{EAE}(53,4 \%)$ foi para o macarrão de formulação padrão, contendo apenas extrato de espinafre. Para o macarrão adicionado de 7,5\% de AT, o $\mathrm{EAE}$ foi de 62\%, uma melhoria de $9 \%$ em relação ao padrão e para o macarrão adicionado de $7,5 \%$ de Ex, o EAE foi de $72,4 \%$, uma melhoria de $19 \%$ em relação ao macarrão padrão.

A Tabela 3 mostra ainda o perfil de aminoácidos não essenciais, bem diferente nos derivados de levedura, comparado com os macarrões em que a proteína predominante é a proteina do trigo. A proteína do trigo é deficiente principalmente em lisina, mas também em treonina, leucina e aminoácidos sulfurados. Apresenta elevados teores de ácido glutâmico e de prolina. Boa parte do ácido glutâmico é proveniente da amida glutamina, que se transforma em ácido glutâmico com liberação de amônia, durante a hidrólise ácida para a análise. 
TABELA 3. Composição em aminoácidos dos derivados de levedura (AT e Ex) e de macarrões enriquecidos com extrato de espinafre mais $7,5 \%$ de AT ou Ex.

\begin{tabular}{|c|c|c|c|c|c|c|}
\hline \multirow{3}{*}{$\begin{array}{l}\text { Aminoácido } \\
(\mathrm{g} / 100 \mathrm{~g} \mathrm{P})^{1}\end{array}$} & \multirow{3}{*}{ AT } & \multirow{3}{*}{ Ex } & \multicolumn{4}{|c|}{ Macarrões } \\
\hline & & & \multirow{2}{*}{$\begin{array}{c}\text { M-ES } \\
\text { FAONWHO }\end{array}$} & \multicolumn{2}{|c|}{ M-ES-AT } & \multirow{2}{*}{$\begin{array}{c}\text { M-ES-Ex } \\
{[8]}\end{array}$} \\
\hline & & & & $7,5 \%$ & $7,5 \%$ & \\
\hline \multicolumn{7}{|l|}{ Essenciais } \\
\hline Treonina & 5,2 & 3,7 & $2,3^{*}$ & $2,6^{*}$ & $2,9^{*}$ & 3,4 \\
\hline $\begin{array}{l}\text { Metionina + } \\
\text { cistina }\end{array}$ & 2,7 & $2,3^{\star}$ & $2,2^{*}$ & $2,2^{\star}$ & 2,5 & 2,5 \\
\hline Valina & 5,4 & 4,7 & 3,5 & 3,6 & 4,1 & 3,5 \\
\hline Leucina & 6,7 & $5,8^{\star \star}$ & $6,4^{*}$ & $6,2^{*}$ & 6,9 & 6,6 \\
\hline Isoleucina & 4,7 & 3,9 & 2,8 & 2,9 & 3,3 & 2,8 \\
\hline $\begin{array}{l}\text { Fenilalanina } \\
+ \text { +tirosina }\end{array}$ & 7,4 & 6,4 & 6,8 & 6,7 & 7,3 & 6,3 \\
\hline Lisina & 9,0 & 7,0 & $3,1^{* *}$ & $3,6^{\star *}$ & $4,2^{* \star}$ & 5,8 \\
\hline Histidina & 2,7 & 2,4 & 2,5 & $1,6^{*}$ & 2,2 & 1,9 \\
\hline Escore (EAE) & 100,0 & $\begin{array}{c}87,8 \% \\
\text { (Leu) }\end{array}$ & $\begin{array}{c}53,4 \% \\
\text { (Lys) }\end{array}$ & $\begin{array}{c}62,0 \% \\
\text { (Lys) }\end{array}$ & $\begin{array}{c}72,4 \% \\
\text { (Lys) }\end{array}$ & \\
\hline \multicolumn{7}{|l|}{ Não essenciais } \\
\hline $\begin{array}{l}\text { Ác. } \\
\text { aspártico }\end{array}$ & 10,3 & 8,8 & 3,8 & 4,5 & 5,5 & \\
\hline Ác. glutâmico & 12,2 & 10,3 & 33,5 & 27,7 & 30,6 & \\
\hline Serina & 5,9 & 4,2 & 4,4 & 4,5 & 4,8 & \\
\hline Prolina & 2,4 & 2,9 & 11,4 & 9,6 & 10,5 & \\
\hline Glicina & 4,0 & 3,8 & 3,5 & 3,4 & 3,9 & \\
\hline Alanina & 7,0 & 6,1 & 2,6 & 3,2 & 3,8 & \\
\hline Arginina & 2,6 & 2,4 & 2,9 & 2,8 & 3,3 & \\
\hline
\end{tabular}

${ }^{1}$ Resultados representam a média de duas determinaç̃es. O triptofano (Try) não aparece entre os aminoácidos essenciais por ser destruído durante a hidrólise ácida para a análise.

${ }^{*}$ Aminoácidos limitantes em relação ao padrão de referência [8];

**Aminoácidos mais limitantes. M-ES, macarrão de formulação padrão com extrato de espinafre; M-ES-AT, macarrão com espinafre mais 7,5\% de autolisado de levedura; M-ES-Ex, macarrão com espinafre mais $7,5 \%$ de extrato de levedura.

\section{3 - Resultados da avaliação nutricional (valor protéico) dos macarrões}

Na Tabela 4 são apresentados alguns indices de avaliação da qualidade da proteína para o macarrão de formulação padrão contendo extrato de espinafre (M-ES) e para os macarrões adicionados de $7,5 \%$ de autolisado (M-ES-AT) ou 7,5\% de extrato (M-ES-Ex) de levedura, comparativamente a uma dieta com $10 \%$ de caseina. Como era esperado, todos os indices deram valores estatisticamente superiores $(p<0,05)$ para a caseina (CAS).

TABELA 4. Índices relativos ao valor protéico dos macarrões contendo extrato de espinafre, não enriquecidos e enriquecidos com 7,5\% de autolisado (AT) ou de extrato (Ex) de levedura.

$\begin{array}{cccc}\text { Tratamentos } & \begin{array}{c}\text { Dv } \\ (\mathbf{\%})\end{array} & \text { NPR } & \begin{array}{c}\text { PDCAAS* }^{*} \\ (\mathbf{\%})\end{array} \\ \text { CAS (padrão) } & 96,5 \pm 0,7^{\mathrm{a}} & 4,3 \pm 0,3^{\mathrm{a}} & 82,3^{1} \\ \text { M-ES (padrão) } & 87,7 \pm 6,9^{\mathrm{b}} & 2,0 \pm 0,3^{\mathrm{c}} & 46,8 \\ \text { M-ES-AT } & 89,0 \pm 3,3^{\mathrm{b}} & 2,5 \pm 0,5^{\mathrm{b}} & 55,2 \\ \text { M-ES-Ex } & 86,7 \pm 4,8^{\mathrm{b}} & 2,8 \pm 0,5^{\mathrm{b}} & 62,8\end{array}$

*EAE x Dv\%; ${ }^{1}$ EAE da literatura [20]: M-ES, macarrão de formulação padrão acrescido de extrato de espinafre; M-ES-AT e M-ES-Ex, macarrões com espinafre acrescidos de $7,5 \%$, respectivamente, de AT ou de Ex de levedura.
A digestibilidade verdadeira (Dv\%) da proteína não apresentou diferença estatística $(p>0,05)$ entre os macarrões com apenas espinafre e os macarrões acrescidos de $7,5 \%$ de AT ou de Ex de levedura. Para o NPR, o macarrão padrão foi estatisticamente inferior $(\mathrm{p}<0,05)$ aos macarrões enriquecidos, tanto com AT como com Ex de levedura. Não houve diferença estatística entre o NPR dos macarrões com $7,5 \%$ de AT ou de Ex. O PDCAAS seguiu a mesma tendência que o NPR, uma vez que este indice foi idealizado [11] para substituir o PER e o NPR. O PDCAAS foi adotado nos Estados Unidos (F.D.A.) como indice obrigatório na rotulagem de alimentos protéicos, por ser de mais rápida e fácil obtenção que o PER ou o NPR.

\section{4 - Avaliação sensorial do macarrão de formulação padrão e de macarrões enriquecidos com diferentes ingredientes}

Foram analisados produtos de dois processamentos diferentes. No primeiro, comparou-se sensorialmente o macarrão de formulação padrão (massa branca) com macarrões acrescidos de $5 \%$ de autolisado (AT) ou extrato $(\mathrm{Ex})$ de levedura.

A Tabela 5 mostra os resultados da avaliação sensorial (aceitabilidade) do macarrão tipo tubo (massa branca) comparativamente à mesma formulação, porém adicionada de $5 \%$ de extrato (Ex) ou de autolisado (AT) de levedura.

TABELA 5. Avaliação sensorial (aceitabilidade) do macarrão tipo tubo (massa branca) adicionado ou não de $5 \%$ de derivado de levedura.

\begin{tabular}{lccc} 
& \multicolumn{3}{c}{ Macarrões } \\
\cline { 2 - 4 } Atributo sensorial & $\begin{array}{c}\mathbf{M} \\
\text { (padrão) }\end{array}$ & $\begin{array}{c}\mathbf{M} \mathbf{- E x} \\
\mathbf{5 \%}\end{array}$ & $\begin{array}{c}\mathbf{M} \mathbf{\text { M A T }} \\
\mathbf{5} \%\end{array}$ \\
Aparência & $6,9 \pm 1,8^{\mathrm{a}}$ & $6,6 \pm 1,6^{\mathrm{a}}$ & $4,6 \pm 2,3^{\mathrm{b}}$ \\
Cor & $6,7 \pm 1,8^{\mathrm{a}}$ & $6,3 \pm 1,4^{\mathrm{a}}$ & $3,8 \pm 2,1^{\mathrm{b}}$ \\
Textura & $6,9 \pm 1,7^{\mathrm{a}}$ & $6,8 \pm 1,6^{\mathrm{a}}$ & $6,5 \pm 1,7^{\mathrm{a}}$ \\
Sabor & $6,9 \pm 1,4^{\mathrm{a}}$ & $7,1 \pm 1,4^{\mathrm{a}}$ & $6,0 \pm 2,0^{\mathrm{b}}$ \\
Aceitação global & $6,8 \pm 1,7^{\mathrm{a}}$ & $6,7 \pm 1,6^{\mathrm{a}}$ & $5,4 \pm 2,0^{\mathrm{b}}$
\end{tabular}

M, macarrão de formulação padrão;
M-Ex, macarrão padrão adicionado de $5 \%$ de extrato (Ex) de levedura; M-AT, macarrão padrão adicionado de $5 \%$ de autolisado (AT) de levedura;

Não houve diferença $(p>0,05)$ em nenhum atributo sensorial avaliado entre o macarrão de formulação padrão e o macarrão adicionado de $5 \%$ de extrato de levedura. Por outro lado, a adição de 5\% de autolisado de levedura à formulação padrão produziu, em quase todos os atributos, um impacto negativo $(\mathrm{p}<0,05)$, com valores de aparência, cor, sabor e aceitação global inferiores aos atribuídos dos macarrões padrão e do adicionado de $5 \%$ de extrato de levedura, exceção à textura da massa que não se alterou em relação aos macarrões padrão e com $5 \%$ de Ex (M-Ex).

Os percentuais de aceitação, indiferença e rejeição referentes aos macarrões da Tabela 5 são apresentados na Tabela 6. 
A julgar pelos dados da Tabela 6 e da Tabela 5, a aceitação global foi de $82,2 \%$ para o macarrão padrão e de $77,8 \%$ para o macarrão adicionado de $5 \%$ de extrato de levedura e não diferiram entre si $(\mathrm{p}>0,05)$. O índice de rejeição máxima foi de $15,5 \%$ para a cor do macarrão padrão e de $17,8 \%$ para a aparência do macarrão com $5 \%$ de extrato de levedura.

TABELA 6. Porcentagens de aceitação, indiferença e rejeição de macarrões tipo tubo (massa branca) sem adição e com adição de 5\% de derivado de levedura (AT ou Ex).

\begin{tabular}{|c|c|c|c|c|c|c|c|c|c|}
\hline \multirow[b]{2}{*}{ Atributo } & \multicolumn{3}{|c|}{ M (padrão) } & \multicolumn{3}{|c|}{$M-\operatorname{Ex}(5 \%)$} & \multicolumn{3}{|c|}{ M - AT (5\%) } \\
\hline & $A(\%)$ & & $1(\%)$ & $A(\%)$ & & $\mid(\%)$ & $A(\%)$ & & $\mid(\%)$ \\
\hline & $\mathbf{R}(\%)$ & & & $\mathbf{R}(\%)$ & & & $R(\%)$ & & \\
\hline Aparência & 82,2 & 4,4 & 13,3 & 77,8 & 4,4 & 17,8 & 44,4 & 6,7 & 48,9 \\
\hline Cor & 79,9 & 6,7 & 15,5 & 75,6 & 13,3 & 15,5 & 28,9 & 6,7 & 64,4 \\
\hline Textura & 84,5 & 2,2 & 13,3 & 84,4 & 6,7 & 13,3 & 75,6 & 8,9 & 15,5 \\
\hline Sabor & 88,9 & 6,7 & 4,4 & 84,4 & 6,7 & 8,9 & 71,1 & 6,7 & 22,2 \\
\hline Aceitação & 82,2 & 4,4 & 13,3 & 77,8 & 6,7 & 15,5 & 57,7 & 6,7 & 35,5 \\
\hline
\end{tabular}

Por outro lado, a aceitação global do macarrão adicionado de $5 \%$ de autolisado de levedura foi de $57,7 \%$, inferior $(\mathrm{p}<0,05)$ à dos macarrões padrão e com $5 \%$ de Ex de levedura.

Os maiores indices de rejeição para o macarrão com $5 \%$ de autolisado (AT) de levedura foram para a aparência da massa $(48,9 \%)$ e para a cor $(64,4 \%)$.

Na Tabela 7 são apresentados os resultados da análise sensorial (aceitabilidade) dos macarrões processados com extrato de espinafre (massa verde), sem e com adição de $7,5 \%$ de autolisado (AT) ou $7,5 \%$ de extrato (Ex) de levedura.

Pelos dados da Tabela 7 verifica-se que a adição de $7,5 \%$ de extrato, ao macarrão massa verde, prejudicou um pouco a aparência e a cor, embora apenas a cor tenha diferido $(\mathrm{p}<0,05)$ em relação ao macarrão padrão. Contudo, 7,5\% de autolisado (AT) melhorou principalmente a textura, o sabor e a aceitação global do macarrão, igualando-se, nesses atributos, aos macarrões padrão e com $7,5 \%$ de adição de $\operatorname{Ex}(p>0,05)$.

TABELA 7. Avaliação sensorial (aceitabilidade) de macarrões com espinafre (massa verde) adicionado ou não de $7,5 \%$ de extrato (Ex) ou autolisado (AT) de levedura.

\begin{tabular}{|c|c|c|c|}
\hline \multirow[b]{2}{*}{ Atributo } & \multicolumn{3}{|c|}{ Macarrões } \\
\hline & $\begin{array}{ll}\text { AT } & \text { M ES } \\
& \text { (padrão) }\end{array}$ & $\begin{array}{c}M \text { - ES - Ex } \\
7,5 \%\end{array}$ & $\begin{array}{l}\text { M - ES - } \\
7,5 \%\end{array}$ \\
\hline Aparência & $6,7 \pm 1,9^{a}$ & $6,0 \pm 2,0^{b}$ & $6,0 \pm 2,0^{b}$ \\
\hline Cor & $6,7 \pm 1,8^{a}$ & $6,2 \pm 1,9^{a, b}$ & $5,7 \pm 2,1^{b}$ \\
\hline Textura & $6,9 \pm 1,6^{a}$ & $6,1 \pm 2,0^{a}$ & $6,7 \pm 1,5^{\mathrm{a}}$ \\
\hline Sabor & $6,9 \pm 1,6^{a}$ & $6,5 \pm 1,9^{a}$ & $6,5 \pm 1,7^{\mathrm{a}}$ \\
\hline Aceitação global & $6,6 \pm 1,7^{\mathrm{a}}$ & $6,3 \pm 1,9^{a}$ & $6,3 \pm 1,7^{\mathrm{a}}$ \\
\hline
\end{tabular}

$\mathrm{M}-\mathrm{ES}=$ macarrão padrão com extrato de espinafre; $\mathrm{M}-\mathrm{ES}-\mathrm{Ex}=$ macarrão massa verde adicionado de $7,5 \%$ de extrato (Ex) de levedura; M-ES-AT $=$ macarrão massa verde adicionado de $7,5 \%$ de autolisado (AT) de levedura.

Os resultados (Tabela 7) mostram que a incorporação de extrato de espinafre à massa de macarrão permite adi- ção de porcentagem mais elevada dos derivados de levedura, diminuindo as diferenças entre o Ex e o AT com respeito à aparência, cor e aceitação global dos produtos.

Os percentuais de aceitação, indiferença e rejeição relativos aos macarrões da Tabela 7 são mostrados na Tabela 8

A julgar pelos dados da Tabela 6 e da Tabela 8, observa-se que a aceitação global do macarrão com adição de apenas extrato de espinafre (padrão) e com adição de espinafre mais $7,5 \%$ de extrato de levedura diminuiu em relação ao macarrão sem espinafre ou com adição de apenas 5\% de Ex. Considerando todos os atributos analisados, apenas a cor melhorou com a elevação de 5 para 7,5\% de Ex de levedura.

TABELA 8. Percentuais de aceitação, indiferença e rejeições de macarrões tipo tubo (massa verde) sem e com adição de 7,5\% de extrato (Ex) ou de autolisado (AT) de levedura.

\begin{tabular}{|c|c|c|c|c|c|c|c|c|c|}
\hline \multirow[b]{2}{*}{ Atributo } & \multicolumn{3}{|c|}{ M - ES (padrão) } & \multicolumn{3}{|c|}{$M-\operatorname{ES}-\operatorname{Ex}(7,5 \%)$} & \multicolumn{3}{|c|}{ M - ES - AT $(7,5 \%)$} \\
\hline & $A(\%)$ & & $\mid(\%)$ & $A(\%)$ & & $\mid(\%)$ & $A(\%)$ & & $1(\%)$ \\
\hline & $\mathbf{R}(\%)$ & & & $\mathbf{R}(\%)$ & & & $\mathbf{R}(\%)$ & & \\
\hline Aparência & 74,5 & 8,5 & 17,0 & 63,8 & 8,5 & 27,7 & 63,8 & 8,5 & 22,7 \\
\hline Cor & 80,8 & 4,3 & 14,9 & 80,8 & 4,3 & 14,9 & 70,2 & 8,5 & 21,3 \\
\hline Textura & 80,8 & 4,3 & 14,9 & 72,4 & 14,9 & 25,5 & 80,8 & 8,5 & 10,6 \\
\hline Sabor & 87,2 & 4,3 & 8,5 & 72,3 & 8,5 & 19,2 & 76,7 & 8,5 & 14,9 \\
\hline Aceitação & 78,7 & 8,5 & 12,8 & 68,1 & 17,0 & 14,9 & 72,3 & 8,5 & 19,2 \\
\hline
\end{tabular}

Para o macarrão contendo autolisado (AT) de levedura, a adição de extrato de espinafre e a elevação de 5 para $7,5 \%$ de AT produziu uma melhora na aceitação de todos os atributos analisados. A aceitação global se elevou de 57,7\% (massa branca com 5\% AT) para 72,3\% (massa verde com $7,5 \%$ AT). A rejeição global, que era de $35,5 \%$ para o primeiro produto, caiu para $19 \%$ no macarrão massa verde com $7,5 \%$ de AT. A rejeição para cor que era de $64,4 \%$ no macarrão branco, com 5\% de AT, caiu para $21 \%$ no macarrão verde com $7,5 \%$ de AT.

\section{4 - CONCLUSÕES}

A adição de 5 ou $7,5 \%$ de derivado de levedura (autolisado e extrato) elevou os niveis de proteina, fibra alimentar e umidade dos macarrões, comparados com uma formulação padrão (sem adições). Proporcionalmente, houve uma diminuição do teor de carboidratos nos produtos adicionados de derivados de levedura.

Com a adição de derivados de levedura houve uma melhora dos escores de aminoácidos essenciais (EAE) e dos PDCAAS (EAE $x$ digestibilidade verdadeira) dos macarrões enriquecidos. Houve também uma melhora significativa na propriedade dos macarrões promoverem crescimento em ratos, avaliados pelo indice NPR.

A adição de $5 \%$ de extrato (Ex) no macarrão massa branca não alterou nenhum dos atributos sensoriais em relação ao padrão. Por outro lado, a adição de 5\% de autolisado (AT) afetou negativamente os atributos sensoriais, exceto a textura, que se manteve igual à do padrão. 
No macarrão massa verde (extrato de espinafre), a adição de $7,5 \%$ de Ex alterou negativamente apenas a aparência em relação ao controle (sem adição), enquanto que $7,5 \%$ de AT piorou a aparência e a cor, mantendo os demais atributos inalterados, em relação ao controle.

No macarrão massa branca, a adição de 5\% de AT diminuiu sensivelmente a aceitação pelo consumidor, enquanto que no macarrão massa verde, a adição de 7,5\% de AT não teve impacto negativo na aceitação global.

A conclusão geral é a de que é possivel adicionar até $5 \%$ de extrato de levedura a um macarrão tipo tubo (massa curta) sem alterar suas características sensoriais. Adicionando-se extrato de espinafre à massa (macarrão massa verde) foi possivel elevar o nivel de adição de derivado de levedura, tanto para o extrato quanto para o autolisado, ainda com boa aceitação.

A adição de derivados de levedura não exigiu nenhuma modificação na tecnologia de fabricação dos macarrões.

\section{5 - REFERÊNCIAS}

[1] A.O.A.C. - Association of Official Agricultural Chemists, Official Methods of Analysis, $16^{\text {th }}$ edition, Washington, D.C., 1998.

[2] ASP, N.G.; JOHANSSON, C.G.; HALMER, H.; SILJESTRÖM, M.A. A rapid enzymatic assay of insoluble and soluble dietary fiber. Journal of Agricultural and Food Chemistry, Washington, v. 31, n. 3, p. 476-482, 1983.

[3] BABAYAN, T.L.; BEZRUKOV, M.G.; LATOV, V.L.; BELIKOV, V.M.; BELAVTSEVA, E.M.; TITOVA, E.F. Induced autolysis of Saccharomyces cerevisiae: morphological effects, rheological effects and dynamics of accumulation of extracellular hydrolysis products. Current Microbiology, New York, v. 5, p. 163-168, 1981.

[4] BLIGH, E.G.; DYER, W.J. A rapid method of total lipid, extraction and purification. Canadian Journal of Biochemicstry and Physiology, Ottawa, v.37, p.911917, 1959.

[5] CABALLERO-CÓRDOBA, G.M.; SGARBIERI, V.C. Nutritional and toxicological evaluation of a yeast (Saccharomyces cerevisiae) biomass and a yeast protein concentrate. Journal of the Science of Food and Agriculture, v. 80, p. 341-351, 2000.

[6] DZIEZAK, J.D. Yeast and yeast derivatives: applications. Food Technology, Chicago, v. 41, n. 2, p. 122-125, 1987.

[7] DZIEZAK, J.D. Yeast and yeast derivatives: definitions, characteristics and processing. Food Technology, Chicago, v. 41, n. 2, p. 104-112, 1987.
[8] F.A.O./W.H.O. - Food and Agriculture Organization/World Health Organization. Protein quality evaluation. Report of a joint FAO/WHO expert consultation, Food and Nutrition Paper n. 51, Rome, 1989, 72p.

[9] FURCO, A.M. Produção de biomassa de levedura em destilarias de álcool. In: "Workshop" sobre Produção de Biomassa de Levedura: Utilização em Alimentação Humana e Animal. Instituto de Tecnologia de Alimentos, Campinas, 1996, p. 52-58.

[10] HALÁSZ, A.; LÁSZTITY, R. Use of yeast biomass in food production. CRC Press, Boca Raton, 1991, 312p.

[11] HENLEY, E.C.; KUSTER, J.M. Protein quality evaluation by protein digestibility corrected amino acid scoring. Food Technology, Chicago, v. 48, n. 4, p. 74-77, 1994.

[12] HERBERT, D.; PHIPPS, P.J.; STRANGER, R.E. Chemical analysis of microbial cells. In: Norris, J.R.; Ribbors, P.W. (Eds). Methods of Enzymology, London, Academic Press, 1971, v. 5B.

[13] KOLLAR, R.; STURDIK, E.; SAJBIDOR, J. Complete fractionation of Saccharomyces cerevisiae biomass. Food Biotechnology, New York, v. 6, n. 3, p. 225-237, 1992.

[14] LAHR FILHO, D.; GHIRALDINI, J.A.; ROSSEL, C.E.V. Estudos de otimização da recuperação de biomassa de levedura em destilarias. In: "Workshop" sobre Produção de Biomassa de Levedura: Utilização em Alimentação Humana e Animal. Instituto de Tecnologia de Alimentos, Campinas, 1996, 59p.

[15] MeIlgaARD, M.; CIVILle, G.V.; CARR, B.T. Sensory evaluation techniques, $3^{\text {rd }}$ edition, CRC Press, Inc., Boca Raton, 1999, 387p.

[16] REED, D.G.; NAGODAWITANA, T.W. Yeast technology, $2^{\text {nd }}$ ed., Van Nostrand Reinhold, New York, 1991, 378p.

[17] REEVES, P.G.; NIELSEN, F.H.; FAHEY Jr., C.C. AIN - 93 purified diet for laboratory rodents: final report on the American Institute of Nutrition ad hoc Committee on the reformulation of the AIN-76 a rodent diet. Journal of Nutrition, Bethesda, v. 123, n. 2, p. 467-472, 1993.

[18] SGARBIERI, V.C. Proteínas em alimentos protéicos: propriedades, degradações, modificações. Ed. Varela, São Paulo, 1996, 517p., p.375-376.

[19] SGARBIERI, V.C.; ALVIM, I.D.; VILELA, I.S.D.; BALDINI, V.L.S.; BRAGAGNOLO, N. Produção piloto de derivados de levedura (Saccharomyces sp.) para uso como ingrediente na formulação de alimentos. Brazilian Journal of Food Technology, v. 2, n. 1/2, p. 119-125, 1999.

\section{6 - AGRADECIMENTOS}

À FAPESP (Fundação de Amparo à Pesquisa do Estado de São Paulo) pelo suporte financeiro para esta pesquisa. 